University of Nebraska - Lincoln

DigitalCommons@University of Nebraska - Lincoln

Faculty Publications: Department of

Entomology

Entomology, Department of

2009

\title{
Video-tracking and On-plant Tests Show Cry1Ab Resistance Influences Behavior and Survival of Neonate Ostrinia nubilalis Following Exposure to Bt Maize
}

\author{
Jarrad R. Prasifka \\ University of Illinois, prasifka@illinois.edu \\ Richard L. Hellmich \\ USDA Agricultural Research Service, Ames, IA \\ Andre L. B. Crespo \\ Syngenta Biotechnology, Inc., Research Triangle Park, NC \\ Blair Siegfried \\ University of Nebraska-Lincoln, bsiegfried1@ufl.edu \\ David W. Onstad \\ University of Illinois
}

Follow this and additional works at: https://digitalcommons.unl.edu/entomologyfacpub

Part of the Entomology Commons

Prasifka, Jarrad R.; Hellmich, Richard L.; Crespo, Andre L. B.; Siegfried, Blair; and Onstad, David W., "Videotracking and On-plant Tests Show Cry1 Ab Resistance Influences Behavior and Survival of Neonate Ostrinia nubilalis Following Exposure to Bt Maize" (2009). Faculty Publications: Department of Entomology. 168.

https://digitalcommons.unl.edu/entomologyfacpub/168

This Article is brought to you for free and open access by the Entomology, Department of at DigitalCommons@University of Nebraska - Lincoln. It has been accepted for inclusion in Faculty Publications: Department of Entomology by an authorized administrator of DigitalCommons@University of Nebraska - Lincoln. 


\title{
Video-tracking and On-plant Tests Show Cry1Ab Resistance Influences Behavior and Survival of Neonate Ostrinia nubilalis Following Exposure to Bt Maize
}

\author{
Jarrad R. Prasifka • Richard L. Hellmich • \\ Andre L. B. Crespo • Blair D. Siegfried • \\ David W. Onstad
}

Revised: 24 April 2009 / Accepted: 24 June 2009

(C) US Government 2009

\begin{abstract}
To examine how resistance to Bacillus thuringiensis (Bt) toxins influences movement and survival of European corn borer (Ostrinia nubilalis [Hübner]) neonates, the responses of Cry1Ab-resistant, -susceptible, and hybrid (F1) larvae were examined using two different techniques. First, using an automated videotracking system, aspects of $O$. nubilalis movement were quantified in the presence of artificial diet incorporating 50\% non-Bt or insect-resistant Cry1 Ab maize tissue. Second, O. nubilalis dispersal and survival were measured $48-72 \mathrm{~h}$ after hatching on a $\mathrm{Cry} 1 \mathrm{Ab}$ maize plant surrounded by two non-Bt maize plants. Video tracking indicated the presence of CrylAb tissue increased the total distance moved $(\mathrm{m})$, time moving $(\%)$, and time away from the diet (\%) for O. nubilalis while decreasing meander (degrees/cm). However, resistant larvae showed reduced movement and increased meander ( $\approx$ localized searching) relative to susceptible or hybrid larvae on diet
\end{abstract}

\section{J. R. Prasifka ( $ه)$}

Energy Biosciences Institute, Institute for Genomic Biology,

University of Illinois, Room 1117, 1206 West Gregory Drive, Urbana, IL 61801-3838, USA

e-mail: prasifka@illinois.edu

R. L. Hellmich

Corn Insects and Crop Genetics Research Unit,

USDA Agricultural Research Service, Ames, IA, USA

A. L. B. Crespo

Syngenta Biotechnology, Inc., Research Triangle Park, NC, USA

B. D. Siegfried

Department of Entomology, University of Nebraska, Lincoln, NB, USA

D. W. Onstad

Department of Natural Resources and Environmental Sciences,

University of Illinois, Urbana, IA, USA 
incorporating Cry1 Ab tissue. Conversely, when placed onto Cry1 Ab maize plants, resistant larvae were more likely than susceptible $O$. nubilalis to disperse onto adjacent non-Bt plants. The difference in on-plant dispersal seems to reflect greater survival after toxin exposure for resistant larvae rather than increased activity. These results suggest that simplified 'Petri dish' tests may not be predictive of larval movement among non-Bt and insect-resistant Bt maize plants. Because models of $O$. nubilalis resistance evolution incorporate various movement and survival parameters, improved data for on-plant behavior and survival of Bt- resistant, -susceptible, and hybrid larvae should help preserve the efficacy of transgenic insect-resistant maize.

Keywords Transgenic $\cdot$ Bacillus thuringiensis $\cdot$ dispersal $\cdot$ movement $\cdot$ resistance management

\section{Introduction}

The behaviors of arthropods exposed to insecticides have been studied to improve the efficacy of pest management (Georghiou, 1972; Lockwood, 1984) and to preserve benefits of biodiversity such as biological pest control (Umoru et al., 1996; Rafalimanana et al., 2002; Prasifka et al., 2008). Behavioral responses of arthropods to the plant-incorporated toxins produced by insect-resistant genetically-modified (GM or transgenic) crops also have been investigated for several pest species (Harris et al., 1997 [Epiphyas postvittana (Walker)]; Ramachandran et al., 1998 [Plutella xylostella (L.)]; Parker and Luttrell, 1999 [Heliothis virescens (F.)]). In particular, data on movement of pests (Davis and Onstad, 2000; Hibbard et al., 2005) have been used to guide the development of resistance management plans for pests of insect-resistant transgenic crops (European corn borer, Ostrinia nubilalis Hübner, [U.S.-EPA, 2001] and corn rootworms, Diabrotica spp., [NCR-46, 2001]). However, relatively fewer studies have investigated how pest behavioral responses to insect-resistant transgenic crops are influenced by alleles that confer resistance to plant-incorporated toxins (but see Gould and Anderson, 1991; Schwartz et al., 1991; Harris et al., 2006).

For $O$. nubilalis, the primary target of the earliest varieties of insect-resistant transgenic maize, behavioral research has been conducted to determine how resistance to plant-incorporated Bacillus thuringiensis (Bt) toxins may impact diet choice and movement for at least three resistant lines established from different populations. Huang et al. (2001) used a line selected for resistance to a combination of several Bt toxins (in DiPel ES, Valent U.S.A. Corporation, Walnut Creek, California), including those found in lepidopteran-resistant $\mathrm{Bt}$ maize, and noted the position of larvae in choice tests. After confinement with untreated artificial diet and three diets with different amounts of $\mathrm{DiPel}$, both resistant and susceptible $O$. nubilalis were most often found on the diet without Bt toxins. Interestingly, early instars of the resistant line were more often found on the control diet than susceptible larvae. Finding relatively more resistant larvae on the control diet could be interpreted as a product of reduced physiological susceptibility to toxins (if toxic effects of the Bt diet render susceptible larvae unable to move away) or a strictly behavioral difference where resistant larvae are inherently more likely to attempt to leave a diet containing Bt toxins; the latter explanation was favored by Huang et al. (2001). Two O. nubilalis lines resistant to the 
Bt toxin Cry1Ab were tested by Prasifka et al. (2009) in no-choice and choice tests with $\mathrm{Bt}$ diets containing up to $50 \%$ tissue for $\mathrm{Bt}$ maize or a related non-Bt variety. Resistant and susceptible control lines were more likely to be found on diets without CrylAb. However, because susceptible larvae were less likely to be found on diets containing Bt-maize, differences in diet choice or position seem to reflect lines' physiological susceptibility to toxins.

Though informative, the laboratory assays used by Huang et al. (2001) and Prasifka et al. (2009) were qualitative rather than quantitative and may not predict $O$. nubilalis larval behavior on lepidopteran-resistant transgenic maize plants. To expand on their work and address some of the uncertainties, additional experiments with Cry1Ab-resistant and -susceptible larvae were conducted using automated video-tracking and on-plant tests. Specifically, experiments were designed to (1) quantify aspects of larval movement in the presence of diets incorporating non-Bt or insect-resistant Bt maize tissue, and (2) determine whether results from 'Petri dish' tests were predictive of larval movement and survival among non-Bt and insectresistant Bt maize plants.

\section{Materials and Methods}

\section{European Corn Borers}

Larvae collected in Kandiyohi County, Minnesota, U.S.A. were used to start CrylAb-resistant and -susceptible lines of O. nubilalis (R-Kandi and S-Kandi in Siegfried et al., 2007). The resistance in R-Kandi is incompletely recessive and appears to be based on three or more loci (Crespo et al., 2009), which does not fit the assumption of recessive resistance based on a single-locus used in many models of resistance evolution. However, relatively high levels of resistance $(\approx 1000$-fold) enable it to be useful for short-term tests on maize plants expressing Cry1 Ab. For simplicity, larvae from R-Kandi, S-Kandi and crosses between colonies (F1) will be referred to as resistant, susceptible and hybrid lines, respectively. Hybrid O. nubilalis were not maintained as a distinct line, but were produced as needed by crossing resistant and susceptible adults; because adults emerged into individual containers, each moth could be sexed and placed into one of two cages (resistant $q \times$ susceptible $\hat{\delta}$ or susceptible $q \times$ resistant $\hat{\jmath}$ ) for mating and egg production.

\section{Video-tracking Trials}

Automated video-tracking software (Ethovision ${ }^{\circledR}$; Noldus Information Technology, 2002) was used to examine potential differences among the lines for aspects of larval movement following exposure to dietary $\mathrm{Cry} 1 \mathrm{Ab}$ from $\mathrm{Bt}$ maize. Diets were modified from a standard $O$. nubilalis diet by replacing $50 \%$ of the dry nutritive ingredients with an equivalent mass of maize leaf tissue from non-Bt (Pioneer 34 N43) or Cry1 Ab-expressing (34 N44) varieties (Reed et al., 1972). Maize tissues were obtained by cutting plants $(\approx \mathrm{V} 10$ stage $)$ at the collar of leaf 10 , and removing leaves 10 and 11; the remaining tissue was freeze-dried, ground $(<1 \mathrm{~mm}$ particle size), and stored at $-80^{\circ} \mathrm{C}$. 
Within $6 \mathrm{~h}$ of hatching, unfed $O$. nubilalis neonates were placed singly into clear enclosed containers (1.9 cm diameter, E and T Kointainer Co., Sidney, Ohio, U.S.A.) with small disc of diet (with non-Bt or Cry1 Ab maize tissue) produced by cutting a cross-section from a cylinder of diet extracted with a \#4 cork borer ( $0.6 \mathrm{~cm}$ diameter). For each $12 \mathrm{~h}$ video-tracking session, 12 containers were placed in a four-by-three group on top of a rigid sheet of acrylic glass and lit from below by two infrared lightemitting diode arrays (Tracksys Ltd., Nottingham, United Kingdom). An infrared camera allowed EthoVision to locate the heads of $O$. nubilalis larvae, which were darker than the background and artificial diet. Recordings of the paths of individual larvae, called tracks, were made for 12 larvae simultaneously, with the center of gravity (for the head) captured as time-series coordinates $(x, y)$ once per second.

Over one hour intervals, Ethovision was used to calculate distance moved $(\mathrm{cm})$, meander (degrees/cm), time away from the diet (\%) and time moving (\%). To remove error produced by system noise or trivial movement, an input filter was used with the minimum distance moved $=0.10 \mathrm{~cm}$. To estimate time moving, larvae were only considered moving if they exceeded an average velocity of $0.04 \mathrm{~cm} / \mathrm{s}$ ( $\approx$ one body length per five seconds) and maintained a pace of at least $0.02 \mathrm{~cm} / \mathrm{s}$ averaged over five second intervals. Though somewhat arbitrary, this criterion appeared useful to distinguish movements associated with sustained feeding from those related to searching or larval irritation. For each of the three lines (resistant, susceptible and hybrid), 30 replicates (= larvae) were observed on non-Bt and Cry1 Ab maize diets.

\section{On-plant Tests}

Greenhouse-grown non-Bt (34 N43) and Cry1Ab (34 N44) maize plants were used to evaluate movement and survival for the $O$. nubilalis lines. Plants were grown in $36 \mathrm{~cm}$ diameter $\left(\approx 175 \mathrm{~cm}^{3}\right)$ pots filled with a porous medium (Premier Pro-mix 'HP', Premier Horticulture Ltd, Quebec, Canada) and fertilized weekly (250300 ppm N-P-K). As the collars of leaves six, seven, or eight became visible (V6V8; Ritchie et al., 1997), plants were moved from the greenhouse into the laboratory. Maize plants were then placed into larger window-box containers to create groups of one Cry1 Ab pot in between two non-Bt pots. Because up to four egg masses per plant do not appear to increase the movement of O. nubilalis between plants (Ross and Ostlie, 1990), three to four masses were placed onto the middle plant in each grouping when they appeared near hatch (at blackhead stage; Mason et al., 1996). Between 48-72 h after larval emergence, all plants were dissected to count the numbers of living and dead larvae. For both the resistant and susceptible lines, ten replicates (=window-boxes) were included.

\section{Statistical Analyses}

All analyses were conducted using SAS statistical software (SAS Institute Inc., 2007). Video-tracking data were calculated over 12 consecutive one hour periods on individual larvae, suggesting a repeated-measures analysis. However, significant interactions (time $\times$ line, time $\times$ diet [with or without Cry1 Ab]) indicated any analysis that included time as a factor also would require testing effects of time within each diet or line in several separate tests, effectively eliminating any simplifying value of 
repeated-measures analysis. As a result, per hour mean values of distance moved, meander, time away from the diet and time moving were calculated for each larva to summarize the $12 \mathrm{~h}$ observation period. A generalized linear model (PROC GLM) was then used to test for the effects of line, diet and a line $\times$ diet interaction on each of the four aspects of larval movement. Comparisons among the treatments were made with least-squares estimated means and $t$-tests. Additionally, the relationships between pairs of video-tracking variables were examined using Pearson's correlation coefficients ( $r$; PROC CORR); to allow for the possibility that relationships between variables (i.e., overall patterns of movement) differed on diets containing $50 \%$ non$\mathrm{Bt}$ or Cry1 Ab maize tissue, correlations were tested separately for each diet type ( $n=90$ observations).

Data from on-plant tests included counts of living and dead larvae on each maize plant in a three-plant grouping. Counts were used to determine the proportion of larvae that (1) survived over the 48-72 h after hatching, or (2) moved off of the central plant onto adjacent non-Bt maize. Since successful movement off of the central Cry $1 \mathrm{Ab}$ plant might logically increase survival, (3) survival also was estimated separately for dispersing larvae (i.e., excluding larvae that remained on $\mathrm{Bt}$ maize). To test for the effect of line (resistant or susceptible) on each of the three proportions, PROC GLM was used. Because the numbers of larvae recovered from the window-box containers covered a broad range $(n=15-78)$, the overall analyses of movement and survival were weighted by the number of larvae found in each group of three plants; for survival of larvae moving off the central (Bt maize) plant, the analysis used the number of larvae collected from the adjacent non-Bt plants as a weighting value.

\section{Results}

Video-tracking Trials

Analysis of movement by $O$. nubilalis neonates showed the total distance moved during $12 \mathrm{~h}$ observations was significantly influenced by line $\left(F_{2,174}=3.65, P=\right.$ $0.028)$, diet $\left(F_{1,174}=61.65, P<0.001\right)$ and a line $\times$ diet interaction $\left(F_{2,174}=3.86, P=\right.$ $0.023)$. Diet containing Cry $1 \mathrm{Ab}$ tissue increased movement of all lines compared to control diet, but among larvae exposed to insect-resistant maize tissue, both susceptible and hybrid larvae moved greater distances than resistant $O$. nubilalis (Fig. 1). Meander (degrees/cm) also was significantly affected by line $\left(F_{2,174}=4.06\right.$, $P=0.019)$ and diet $\left(F_{1,174}=239.39, P<0.001\right)$. Larvae on control diet showed a greater amount of turning per $\mathrm{cm}$ of movement when compared to larvae on Cry1 Ab tissue. However, on diet incorporating CrylAb maize, resistant larvae had higher meander values than susceptible and hybrid $O$. nubilalis (Fig. 1). Only diet type was shown to affect the percentage of time moving $\left(F_{1,174}=74.88, P<0.001\right)$ and time away from the diet $\left(F_{1,174}=130.74, P<0.001\right)$, with greater observed values for larvae exposed to diet containing $\mathrm{Bt}$ maize tissue (Fig. 2).

Significant correlations $(P<0.05)$ between aspects of larval movement were detected, but were generally weak $(r<0.50)$ or moderate $(r<0.70)$. For larvae exposed to non-Bt maize tissue, all pairwise comparisons of variables showed significant 


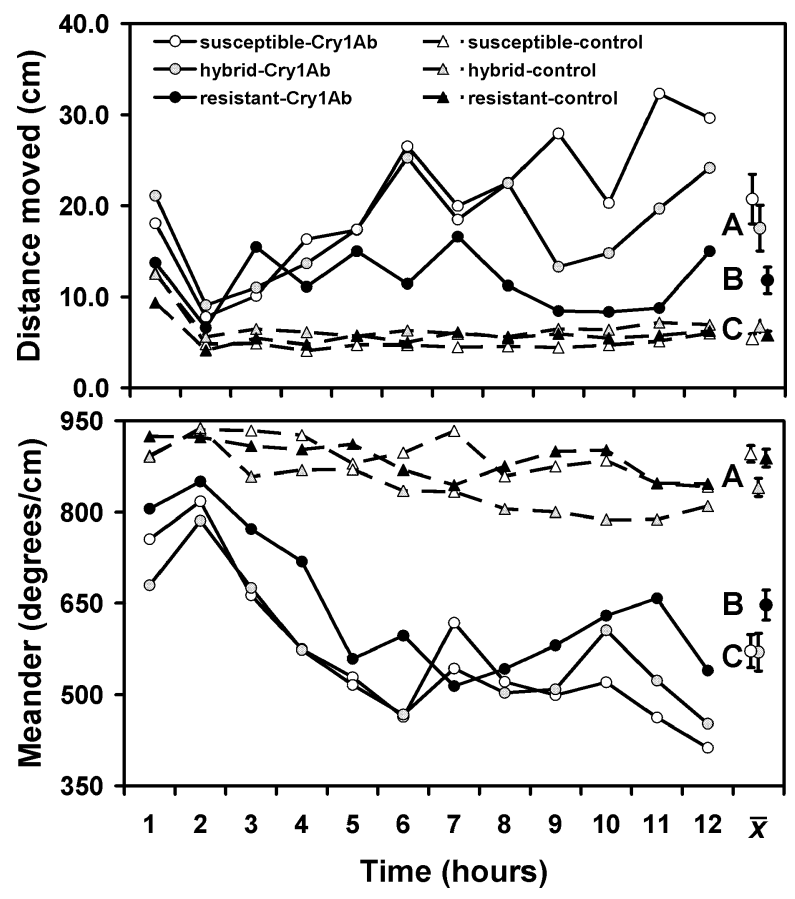

Fig. 1 Distance moved and meander (mean $\pm \mathrm{SE}$ ) for neonate $O$. nubilalis confined with artificial diets containing 50\% Cry $1 \mathrm{Ab}$ or non-Bt corn tissue. Significant differences among Cry1 Ab -resistant, -susceptible and hybrid lines on diets with Cry1 Ab (solid lines) or non-Bt corn tissue (dashed lines) are indicated by different capital letters.

correlations, except total distance moved and the percentage of time moving (Table 1). On diet containing Cry1 Ab maize tissue, all pairwise correlations were significant, and the strength of some correlations (e.g., time moving and distance moved, time moving and meander) was greater than for larvae on non-Bt tissue (Table 1).

On-plant Tests

Similar numbers of resistant $(n=398)$ and susceptible $(n=352)$ O. nubilalis larvae were recovered from dissections of maize plants. However, susceptible and resistant lines differed in both the proportion of larvae dispersing onto adjacent non-Bt maize plants $\left(F_{1,18}=4.49, P=0.048\right)$ and the proportion that survived the $48-72 \mathrm{~h}$ period after hatch $\left(F_{1,18}=13.34, P=0.002\right)$ (Fig. 3). Movement off of Cry1Ab maize and survival both were greater for resistant $O$. nubilalis. When survival was estimated only for larvae that dispersed onto adjacent non-Bt plants, the resistant $O$. nubilalis still had a higher proportion of surviving larvae $\left(F_{1,18}=6.75, P=0.018\right)$ (Fig. 3).

\section{Discussion}

Brief (12 h) video-tracking trials indicated that aspects of larval movement were similar among Cry1Ab-resistant, -susceptible and hybrid lines when O. nubilalis 


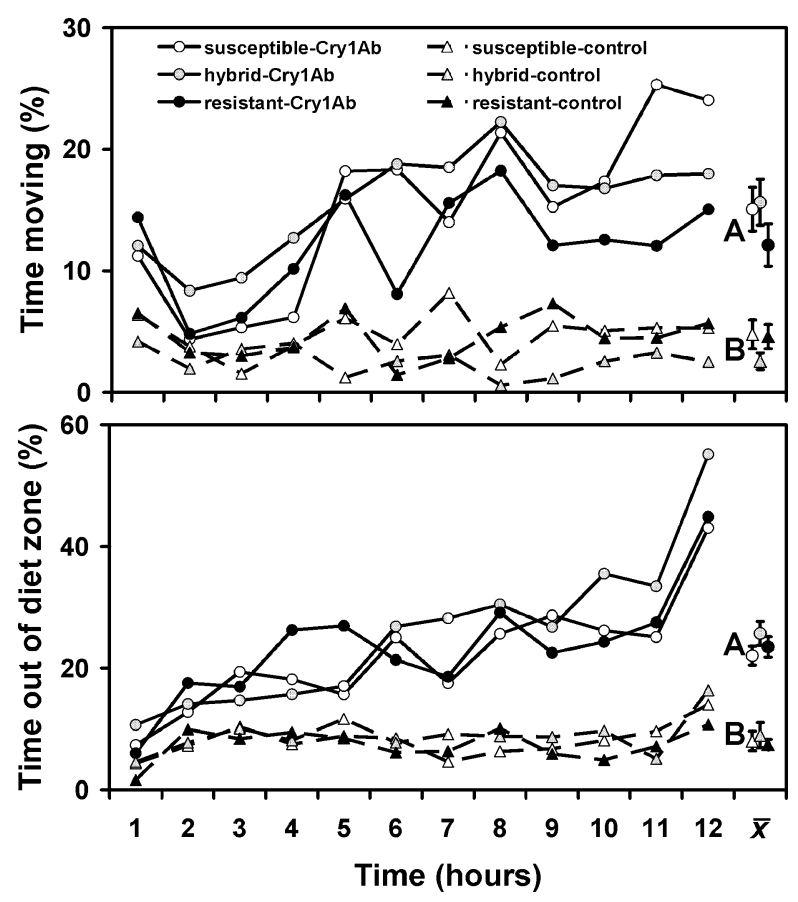

Fig. 2 Percentages of time moving and time outside of a zone surrounding diet (mean $\pm \mathrm{SE}$ ) for neonate O. nubilalis confined with artificial diets containing $50 \%$ Cry1 Ab or non-Bt corn tissue. Significant differences among Cry1Ab-resistant, -susceptible and hybrid lines on diets with Cry1 Ab (solid lines) or non-Bt corn tissue (dashed lines) are indicated by different capital letters.

were provided diet incorporating non-Bt maize tissue. On diet containing Cry1 Ab maize, all lines moved greater total distances, spent more time moving, more time away from Cry1 Ab-maize diet and displayed less turning per unit moved (meander) relative to the non-Bt diet; however, resistant lines moved a lower total distance and displayed more meandering than susceptible or hybrid larvae (Figs. 1 and 2). When O. nubilalis egg masses were placed onto potted Bt maize, a greater percentage of Cry1Ab-resistant larvae moved onto adjacent non-Bt maize plants when compared with the susceptible line. Resistant larvae were also more likely to survive the 48$72 \mathrm{~h}$ period between hatching and the dissection of plants (Fig. 3).

Table 1 Pearson's Correlation Coefficients ( $r$ ) Between Aspects of Larval Movement from Video-tracking for Trials with Diets Containing 50\% Non-Bt (Upper Right Values) or Cry1Ab Corn Tissue (Lower Left Values)

\begin{tabular}{lllll}
\hline Variable & $\begin{array}{l}\text { Distance moved } \\
(\mathrm{cm})\end{array}$ & $\begin{array}{l}\text { Meander } \\
(\text { degrees } / \mathrm{cm})^{1}\end{array}$ & Time moving (\%) & $\begin{array}{l}\text { Time out of diet } \\
\text { zone (\%) }\end{array}$ \\
\hline $\begin{array}{llll}\text { Distance moved } \\
\text { Meander }\end{array}$ & $-0.600^{*}$ & $-0.465^{*}$ & -0.002 & $-0.348^{*}$ \\
Time moving & $0.731^{*}$ & $-0.702^{*}$ & $-213^{*}$ & $0.212^{*}$ \\
Time out of diet zone & $0.222^{*}$ & $-0.217^{*}$ & $0.216^{*}$ & $-355^{*}$ \\
\hline
\end{tabular}

\footnotetext{
${ }^{1}$ Asterisks indicate significant $(\alpha<0.05)$ correlations between variables $(n=90$ observations $)$.
} 


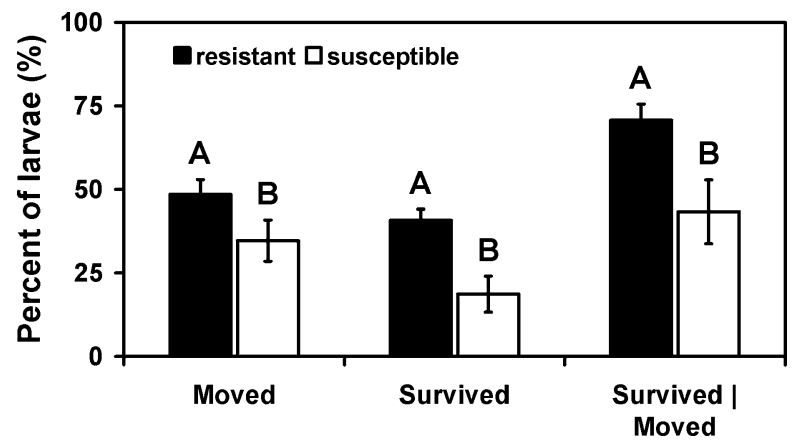

Fig. 3 Percentages of $O$. nubilalis neonates that moved off of Cry1Ab plants or survived (mean $\pm \mathrm{SE}) 48$ $72 \mathrm{~h}$ after hatch. The category Survived | Moved estimates $O$. nubilalis survival only for larvae that successfully moved onto adjacent non-Bt plants. Significant differences among resistant and susceptible lines for each category are indicated by different capital letters.

Interpretation of the video-tracking data is relatively straightforward. While all lines responded to Bt maize diet with increased movement, Cry1 Ab-resistant larvae showed a lower total distance moved ( $\approx$ average velocity with observation times equal across trials) and a higher meander (i.e., more turning) relative to susceptible and hybrid O. nubilalis. The simplest explanation is that susceptible and hybrid larvae were more irritated by dietary Cry1 Ab. The relatively greater distances moved for susceptible and hybrid larvae agree with the results of Prasifka et al. (2009), which showed resistant larvae are less likely to move off of diets containing moderate (10-50\%) amounts of Cry1Ab maize tissue. Likewise, the lower meander for susceptible and hybrid O. nubilalis is consistent with ranging behavior rather than the localized search that is seen when an acceptable food source is detected (Strnad and Dunn, 1990; with western corn rootworm larvae). The lack of significant differences for percentage of time spent away from diet containing Bt maize tissue may be related to the fact that the area covered by the diet was relatively large (diet diameter $\approx 1 / 3$ container diameter), but it is not clear why irritation by dietary Cry1Ab did not produce differences among the lines in the percentage of time moving.

Pairs of variables intended to represent different aspects of larval movement were usually significantly correlated (Table 1 ). However, the strength of most correlations $(r<0.70)$ indicates that any two variables generally represented related, but not redundant components of larval behavior. For larvae confined with CrylAb diet, more correlations were significant and the strength of correlations increased, suggesting that overall patterns of behavior changed with exposure to Bt tissue. In particular, stronger correlations between the percentage of time moving with both distance moved and meander correspond to the observed pattern of larvae confined with Cry1 Ab diet circling the perimeter of the containers after several hours.

The video-tracking observations predict that susceptible larvae should be more likely to move off of Cry $1 \mathrm{Ab}$ maize. However, on-plant trials indicated the opposite, as resistant larvae were about $40 \%$ more likely to move from lepidopteran-resistant maize to an adjacent non-Bt plant. The most plausible explanation for the discrepancy between the "Petri dish" results and on-plant tests is the differences in length of trials; while no mortality occurred during the video-tracking, high but 
differing levels of mortality between resistant and susceptible lines (Fig. 3) likely meant that even if resistant larvae moved more slowly, on average more resistant larvae survived long enough to disperse onto adjacent non-Bt plants.

The on-plant tests also permit comparisons to simulations of O. nubilalis movement and resistance evolution. Based on unpublished observations, Onstad and Gould (1998) estimated 90\% of all larvae (resistant, susceptible and hybrid) would disperse off of $\mathrm{Bt}$ maize. However, the on-plant observations of $36 \%$ (susceptible) and 51\% (resistant) movement off of Bt maize are significantly lower than $90 \%$ (Fig. 3); lower estimates of dispersal suggest susceptible larvae may have significantly greater mortality in mixtures of Bt and non-Bt maize (seed mixtures) than estimated by Onstad and Gould (1998), and the evolution of resistance to Bt maize would tend to be faster. Onstad and Gould (1998) and Davis and Onstad (2000) also considered the survival of larvae moving off of Bt maize to be a key parameter, using values of $94 \%$ and $50 \%$ for the survival of susceptible larvae relative to resistant $O$. nubilalis. The observed relative survival of susceptible larvae moving off of Bt maize in the on-plant tests was about $60 \%$ (susceptible/resistant= $43 \% / 71 \%$ ), supporting the conclusion of Davis and Onstad (2000) that 50\% mortality (relative to resistant larvae) is a realistic consequence for susceptible larvae feeding on Bt maize before dispersal.

Though results from video-tracking (short-duration, small scale) and on-plant (longer-term, larger-scale) observations differed, both approaches provide complementary information on the behavioral responses associated with resistance to $\mathrm{Bt}$ toxins. To obtain more complete information on how resistance influences behavior and the potential for field-evolved resistance to lepidopteran-resistant $\mathrm{Bt}$ maize, additional research is needed for hybrid $O$. nubilalis, as the magnitude of differences between hybrid and fully-susceptible insects determines the course of resistance evolution (Tabashnik et al. 2004). Additionally, data on behavior and survival of $O$. nubilalis resistant to $\mathrm{Bt}$ toxins are needed for a several maize hybrids incorporating single and multiple insect-resistance traits, as current and pending Bt maize varieties will likely be planted as a landscape mosaic in the foreseeable future.

Acknowledgements This research was a joint contribution from the USDA Agricultural Research Service and the Iowa Agriculture and Home Economics Experiment Station, Ames (Project3543). This article reports the results of research only. Mention of a proprietary product does not constitute an endorsement or a recommendation by Iowa State University or USDA for its use. Cindy Backus (Iowa State University) helped conduct the laboratory trials. Research was funded by a grant from the USDA Biotechnology Risk Assessment Research Grants Program.

\section{References}

Crespo, ALB, Spencer TA, Alves AP, Hellmich RL, Blankenship EE, Magalhaes LC, Siegfried BD (2009) On-plant survival and inheritance of resistance to Cry1 Ab toxin from Bacillus thuringiensis in a fieldderived strain of European corn borer, Ostrinia nubilalis. In Press Pest Manag Sci

Davis PM, Onstad DW (2000) Seed mixtures as a resistance management strategy for European corn borers (Lepidoptera: Crambidae) infesting transgenic corn expressing CrylAb protein. J Econ Entomol 93:937-948

Georghiou GP (1972) Evolution of resistance to pesticides. Ann Rev Ecol System 3:133-168 
Gould F, Anderson A (1991) Effects of Bacillus thuringiensis and HD-73 delta-endotoxin on growth, behavior, and fitness of susceptible and toxin-adapted strains of Heliothis virescens (Lepidoptera: Noctuidae). Environ Entomol 20:30-38

Harris MO, Mafile'o F, Dhana S (1997) Behavioral responses of light brown apple moth neonate larvae on diets containing Bacillus thuringiensis formulations of endotoxins. Entomol Exp Appl 84:207-219

Harris MO, Markwick N, Sandanayake M (2006) Is resistance to Bacillus thuringiensis endotoxin Cry1Ac associated with a change in the behavior of light brown apple moth larvae (Lepidoptera: Tortricidae)? J Econ Entomol 99:508-518

Hibbard BE, Vaughn TT, Oyediran IO, Clark TL, Ellersieck MR (2005) Effect of Cry3Bb1-expressing transgenic corn on plant-to-plant movement by western corn rootworm larvae (Coleoptera: Chrysomelidae). J Econ Entomol 98:1126-1138

Huang FN, Buschman LL, Higgins RA (2001) Larval feeding behavior of Dipel-resistant and susceptible Ostrinia nubilalis on diet containing Bacillus thuringiensis (Dipel ES). Entomol Exp Appl 98:141-148

Lockwood JA, Sparks TC, Story RN (1984) Evolution of insect resistance to insecticides: a reevaluation of the roles of physiology and behavior. Bull Entomol Soc Am 30:41-51

Mason CE, Rice ME, Calvin DD, Van Duyn JW, Showers WB, Hutchison WD, Witkowski JF, Higgins RA, Onstad DW, Dively GP (1996) European corn borer ecology and management. North Central Regional Extension Publication 327, Iowa State University, Ames. 57 pp.

NCR-46. (2001) Letter to Sharlene Matten, EPA Office of Pesticide Programs regarding Section 3 registration of Cry3Bblagainst corn rootworms. North Central Region Committee for Development, Optimization and Delivery of Management Strategies for Corn Rootworms. http://www.entomology. umn.edu/Faculty/ostlie/NCR46_EPA_Letter.pdf

Noldus Information Technology (2002) EthoVision video-tracking system for automation of behavioral experiments: Reference Manual Version 3.0. Noldus Information Technology bv. Wageningen, The Netherlands

Onstad DW, Gould F (1998) Modeling the dynamics of adaptation to transgenic maize by European corn borer (Lepidoptera: Pyralidae). J Econ Entomol 91:585-593

Parker CD, Luttrell RG (1999) Interplant movement of Heliothis virescens (Lepidoptera: Noctuidae) larvae in pure and mixed plantings of cotton with and without expression of the Cry1Ac deltaendotoxin protein of Bacillus thuringiensis Berliner. J Econ Entomol 92:837-845

Prasifka JR, Lopez MD, Hellmich RL, Prasifka PL (2008) Effects of insecticide exposure on movement and population size estimates of predatory ground beetles (Coleoptera: Carabidae). Pest Manag Sci 64:30-36

Prasifka JR, Hellmich RL, Sumerford DV, Siegfried BD (2009) Bacillus thuringiensis resistance influences European corn borer (Lepidoptera: Crambidae) larval behavior following exposure to Cry1Ab. J Econ Entomol 102:781-787

Rafalimanana H, Kaiser L, Delpuech JM (2002) Stimulating effects of the insecticide chlorpyrifos on host searching and infestation efficacy of a parasitoid wasp. Pest Manag Sci 58:321-328

Ramachandran S, Buntin GD, All JN, Raymer PL, Stewart CN (1998) Movement and survival of diamondback moth (Lepidoptera: Plutellidae) larvae in mixtures of nontransgenic and transgenic canola containing a cryIA(c) gene of Bacillus thuringiensis. Environ Entomol 27:649-656

Reed GL, Showers WB, Huggans JL, Carter SW (1972) Improved procedures for mass rearing European corn borer (Lepidoptera: Pyralidae). J Econ Entomol 65:1472-1476

Ritchie SW, Hanway JJ, Benson GO (1997) How a corn plant develops. Iowa State Univeristy of Science and Technology Special Report No. 48. 21 pp.

Ross SE, Ostlie KR (1990) Dispersal and survival of early instars of European corn borer (Lepidoptera: Pyralidae) in field corn. J Econ Entomol 83:831-836

SAS Institute Inc. (2007) SAS OnlineDoc 9.1.3. SAS Institute, Cary, North Carolina, U.S.A.

Schwartz JM, Tabashnik BE, Johnson MW (1991) Behavior and physiological responses of susceptible and resistant diamondback moth larvae to Bacillus thuringiensis. Entomol Exp Appl 61:179-187

Siegfried BD, Spencer T, Crespo AL, Storer NP, Head GP, Owens ED, Guyer D (2007) Ten years of Bt resistance monitoring in the European corn borer: what we know, what we don't know, and what we can do better. Amer Entomol 53:208-214

Strnad SP, Dunn PE (1990) Host search behavior of neonate western corn rootworm (Diabrotica virgifera virgifera). J Insect Physiol 36:201-205 
Tabashnik BE, Gould F, Carrière Y (2004) Delaying evolution of insect resistance to transgenic crops by decreasing dominance and heritability. J Evol Biol 17:904-912

Umoru PA, Powell W, Clark SJ (1996) Effect of pirimicarb on the foraging behavior of Diaeretiella rapae (Hymenoptera: Braconidae) on host-free and infested oilseed rape plants. Bull Entomol Res 86:193-201

U.S.-EPA (2001) Insect resistance management. In Biopesticides Registration Action Document Bacillus thuringiensis Plant-Incorporated Protectants. United States Environmental Protection Agency, Washington, DC. http://www.epa.gov/oppbppd1/biopesticides/pips/bt_brad2/4-irm.pdf 